\title{
The yeast Xrs2 complex functions in $S$ phase checkpoint regulation
}

\author{
Damien D'Amours and Stephen P. Jackson ${ }^{1}$ \\ Wellcome Trust and Cancer Research Campaign Institute of Cancer and Developmental Biology, and Department \\ of Zoology, University of Cambridge, CB2 1QR Cambridge, UK
}

The Nbs1 complex is an evolutionarily conserved multisubunit nuclease composed of the Mre11, Rad50, and Nbs1 proteins. Hypomorphic mutations in the NBS1 or MRE11 genes in humans result in conditions characterized by DNA damage sensitivity, cell cycle checkpoint deficiency, and high cancer incidence. The equivalent complex in the yeast Saccharomyces cerevisiae (Xrs2p complex) has been implicated in DNA double-strand break repair and in telomere length regulation. Here, we find that $x r s 2 \Delta$, mre11s, and rad50 mutants are markedly defective in the initiation of the intra-S phase checkpoint in response to DNA damage. Furthermore, the absence of a functional Xrs2p complex leads to sensitivity to deoxynucleotide depletion and to an inability to efficiently slow down cell cycle progression in response to hydroxyurea. The checkpoint appears to require the nuclease activity of Mre11p and its defect is associated with the abrogation of the Tel1p/Mec1p signaling pathway. Notably, DNA damage induces phosphorylation of both Xrs2p and Mre11p in a Tel1p-dependent manner. These results indicate that the Tel1p/ATM signaling pathway is conserved from yeast to humans and suggest that the Xrs2p/Nbs1 complexes act as signal modifiers.

[Key Words: Xrs2p complex; checkpoint; Nijmegen breakage syndrome; Mre11; ATM]

Received May 21, 2001; revised version accepted July 13, 2001.

Eukaryotic cells have evolved surveillance mechanisms called checkpoints to monitor the integrity of their genome. The DNA damage checkpoint consists of a network of signaling proteins that acts to detect DNA lesions and signal their presence to cell cycle regulators (Michelson and Weinert 2000). This results in the slowing down of the cell cycle, which is thought to provide time for DNA repair factors to prevent the damage becoming fixed as a permanent genetic change (for review, see Foiani et al. 2000).

The mechanisms leading to the detection of DNA lesions by checkpoint factors and the identity of the proteins responsible for the initiation of the checkpoint response have yet to be clarified. However, recent evidence indicates that in many cases the formation of DNA lesions per se may be insufficient to initiate the transduction cascade leading to cell cycle arrest in damaged cells. Indeed, in Saccharomyces cerevisiae rad14 or rad2 mutants, irreparable UV damage remains undetected until the early stages of S phase, whereas nucleotide excision repair (NER)-proficient cells detect this type of damage readily in $G_{1}$ (Siede et al. 1994; Neecke et al. 1999). Similarly, activation of the p53 response in UV-treated human NER-deficient $\left(X P A^{-}\right)$cells is not observed in the absence of DNA replication (Nelson and Kastan 1994).

\footnotetext{
${ }^{1}$ Corresponding author.
}

E-MAIL spj13@mole.bio.cam.ac.uk; FAX 1223-334089.

Article and publication are at http://www.genesdev.org/cgi/doi/10.1101/ $\operatorname{gad} .208701$.
Together, these observations indicate that UV lesions have to be processed to a signaling-competent state (secondary lesion) before checkpoint responses can be elicited. Accordingly, the existence of a checkpoint-activating nuclease (signal-modifier) has been proposed and recent studies indicate that single-stranded DNA (ssDNA) may be one of the secondary lesions that activates the DNA damage checkpoint (Garvik et al. 1995; Lydall and Weinert 1995; Lee et al. 1998).

The increased ability to detect irreparable UV damage in $S$ phase cells (compared to $G_{1}$ cells in the examples described above) is not restricted to eukaryotes, as the induction of the SOS response in Escherichia coli also depends on the initiation of DNA replication (Sassanfar and Roberts 1990). This raises the possibility that some nuclease(s) act specifically during $S$ phase to ensure that checkpoint mechanisms are induced efficiently and that no lesions are transformed into stable mutations during the replication process. The critical importance of the intra-S phase checkpoint in preventing the fixation of DNA lesions is particularly relevant in the prevention of cancer. Indeed, individuals afflicted with genetic disorders characterized by a loss of the intra-S phase checkpoint, such as ataxia telangiectasia (AT) and Nijmegen breakage syndrome (NBS), are among those who suffer the most severe predisposition to cancer (for reviews, see Jeggo et al. 1998; Petrini 2000). Cells isolated from AT or NBS patients do not show the typical slowing down of DNA replication seen in the presence of DNA-damaging agents such as bleomycin or ionizing radiation (IR; 
The Xrs2p complex is required for S phase control

Painter and Young 1980; Taalman et al. 1983). Instead, they carry on DNA synthesis and cell cycle progression continues unperturbed, a phenomenon known as radioresistant DNA synthesis (RDS; Painter and Young 1980).

The IR sensitivity and RDS phenotype of AT and NBS cells suggest that the products of the genes mutated in these cells-ATM and Nbs1, respectively-are normally involved in the early steps of the detection and signaling of DNA damage (Petrini 2000). However, whether these proteins are DNA damage sensors, signal-modifiers, or transducers is unclear. Interestingly, the Nbs1 protein has several properties consistent with a role as signalmodifier in the checkpoint transduction cascade. First, despite being IR-sensitive and showing chromosome instability, NBS cells have no gross defects in their abilities to repair DNA damage (Jeggo et al. 1998; Petrini 2000). Second, NBS cells exhibit defects in cell cycle control in S phase (Taalman et al. 1983). Third, Nbs1 is a member of a multisubunit complex that includes the human Rad50 (hRad50) and hMre11 proteins (Carney et al. 1998). Hypomorphic mutations in hMRE11 have been shown to cause an ataxia telangiectasia-like disease (ATLD) which is similar to the checkpoint-deficient AT disorder (Stewart et al. 1999). Furthermore, Mre11 has nuclease activity that can generate extensive regions of ssDNA, which has been shown to activate checkpoints strongly (Garvik et al. 1995; Lydall and Weinert 1995; Lee et al. 1998; Usui et al. 1998). More recently, it has been shown that Nbs1 is phosphorylated by ATM in response to DNA damage and that this is required to mediate an $S$ phase arrest in the presence of DNA damage (for reviews, see Michelson and Weinert 2000; Rhind and Russell 2000). Nevertheless, it has been difficult to identify the precise molecular role(s) of the Nbs1 complex during DNA damage signaling in higher eukaryotes because the genes encoding Mre11, Rad50, and Nbs1 are required for cellular viability (Xiao and Weaver 1997; Luo et al. 1999; Zhu et al. 2001).

The Nbs1 complex is conserved evolutionarily in eukaryotes. hMre11 and hRad50 were originally identified because of their homology with Mre11p and Rad50p, two members of the Xrs2p complex in S. cerevisiae (Alani et al. 1989; Johzuka and Ogawa 1995). Deletion of the genes encoding the members of the Xrs2p complex in yeast result in pleiotropic effects including DNA damage sensitivity, DNA repair deficiency, hyper-recombination, telomere shortening, and impaired meiotic progression (for review, see Haber 1998). Surprisingly, however, no clear checkpoint defects have so far been reported for yeast with mutations in the Xrs2p complex (Kironmai and Muniyappa 1997). The evolutionary conservation of the checkpoint functions of the Xrs2p and Nbs1 complexes has been further put in doubt by the lack of clear sequence homology between Xrs2p and Nbs1 (Carney et al. 1998; Varon et al. 1998). Nevertheless, we show here that the $S$. cerevisiae Xrs2p complex has a critical role in the initiation of the intra-S phase checkpoint. We discuss these findings in regard to the evolutionary conservation of the ATM signaling pathway and the functions of the Xrs $2 \mathrm{p} / \mathrm{Nbs} 1$ complexes in these events.

\section{Results}

Yeast lacking a functional Xrs $2 p$ complex are hypersensitive to replicative stress

To gain insight into the molecular basis for the $S$ phase checkpoint defect associated with NBS and ATLD, we decided to study the potential role of the $S$. cerevisiae Xrs2p complex in $S$ phase regulation. To this end, we examined the sensitivity of various DNA DSB repair and checkpoint mutants to replicative stress induced by the drug hydroxyurea (HU). HU is an inhibitor of ribonucleotide reductase, the rate-limiting enzyme in deoxyribonucleotide (dNTP) biosynthesis. Depletion of dNTPs activates the DNA replication checkpoint, which slows progression through S phase (Desany et al. 1998). Furthermore, initiation of DNA replication in the presence of high levels of HU causes DNA DSBs (Merrill and Holm 1999, and references therein).

Yeast cells defective in the members of the Xrs2p com-

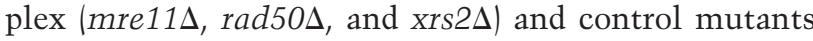
defective in DNA repair (rad51s, yku70s), or defective in the DNA replication (rad53 $\Delta$ ) and DNA damage $($ rad53s, rad9s) checkpoints, were serially diluted onto plates containing various concentrations of HU (Fig. 1). High concentrations of HU cause a block to DNA replication and a significant number of DSBs, whereas low concentrations of $\mathrm{HU}$ cause only a mild retardation in DNA replication and many fewer DSBs (Merrill and Holm 1999). All mutants tested display significant growth defects on plates containing 200 mM HU (Fig. 1). This lethality is at least partially a consequence of DSB formation because rad9s and yku70s mutants display

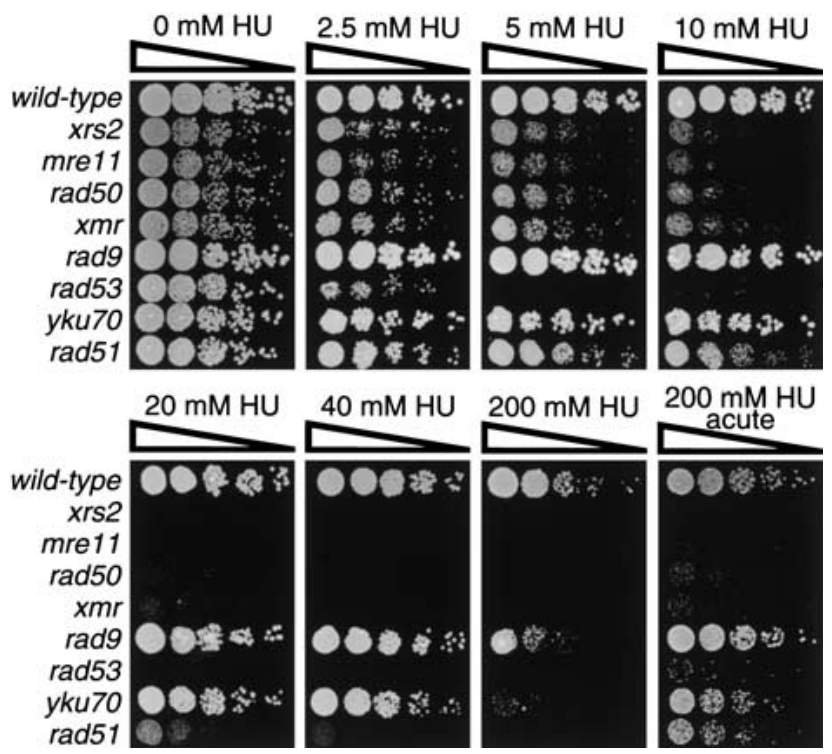

Figure 1. Hypersensitivity of xrs $2 \Delta$, mre $11 \Delta$, and rad50s mutants to replicative stress. Fivefold serial dilution of yeast cells were plated on YPAD containing various concentrations of HU. For the HU acute hypersensitivity experiment, exponential cultures were grown for $9 \mathrm{~h}$ in liquid YPAD containing $200 \mathrm{mM}$ HU before being washed and plated on YPAD plates. Relevant genotypes are shown on the left side of the panels. 
little or no sensitivity to growth in the presence of 40 $\mathrm{mM}$ HU (Fig. 1). As expected for a DNA replication checkpoint mutant, the rad53 $\Delta$ strain is sensitive to all the concentrations of HU tested (Fig. 1). Notably, strains with mutations in members of the Xrs2p complex (referred to hereafter as $\mathrm{xmr}$ mutants) show marked sensitivity to $\mathrm{HU}$; some sensitivity can be seen with concentrations of $\mathrm{HU}$ as low as $5 \mathrm{mM}$, whereas the $\mathrm{xmr}$ mutants become highly sensitive at $10 \mathrm{mM} \mathrm{HU}$ and are almost completely dead at $20 \mathrm{mM} \mathrm{HU}$ (Fig. 1). The similar responses of the single and triple $x m r$ mutants indicate that null mutations in XRS2, MRE11, and RAD50 are epistatic in their effects on HU sensitivity. Interestingly, the sensitivity of the $x \mathrm{mr}$ mutants to $10 \mathrm{mM} \mathrm{HU}$ is much greater than that of the rad51 $\Delta$ mutant (Fig. 1). This is in contrast with the more severe radiosensitivity of rad51 mutants when compared with rad50 mutants (Saeki et al. 1980) and suggests that the HU sensivity of the $x m r$ mutants might not primarily reflect a homologous recombination (HR) defect.

To differentiate between a role for the Xrs2p complex in DSB repair or in checkpoint regulation, we examined the ability of the mutant strains to survive a transient period of growth in the presence of high concentrations of HU (HU hypersensitivity assay). This acute treatment causes severe lethality in mutants that are specifically defective in the DNA replication checkpoint but not in mutants affected in DNA repair or in other DNA damage checkpoints (Allen et al. 1994). Thus, it is possible to discriminate between a DNA replication checkpoint defect and a DNA repair defect in a strain sensitive to continuous treatment with $\mathrm{HU}$, on the basis of its additional sensitivity (hypersensitivity) to an acute treatment. Strikingly, whereas the sensitivity of rad51s, yku70s, and rad $9 \Delta$ mutant strains to chronic treatment with 200 $\mathrm{mM} \mathrm{HU}$ is significantly reversed under acute conditions, this is not the case for the xmr mutants (Fig. 1). Indeed, the behavior of the $x m r$ mutants in this assay is similar to that of the rad53 $\Delta$ mutant, which has a known defect in S phase regulation (Allen et al. 1994). The similarities between the responses of $\mathrm{xmr}$ and rad530 mutants and the fact that a DNA repair deficiency per se does not result in checkpoint deficiency (Fig. 1; Paulovich et al. 1997) suggest that the HU hypersensitivity of the xmr mutants is due to defective regulation of $\mathrm{S}$ phase progression.

The Xrs $2 p$ complex is required to slow DNA synthesis in the presence of replicative stress

One prediction from the above results is that $\mathrm{xmr} \mathrm{mu}$ tants may be defective in their ability to slow DNA synthesis in the presence of replicative stress. To test this, cells were arrested in $G_{1}$ with $\alpha$-factor, released from $G_{1}$ in the presence of a low concentration $(40 \mathrm{mM})$ of $\mathrm{HU}$, and DNA content was monitored by flow cytometry (FACS) to assess the kinetics of DNA replication (Fig. 2). When released from $\mathrm{G}_{1}$ in the absence of $\mathrm{HU}$, there was no detectable difference in the kinetics of cell cycle progression in the xrs $2 \Delta$ and $x r s 2 \Delta$ mre $11 \Delta$ rad50 $(x m r \Delta)$

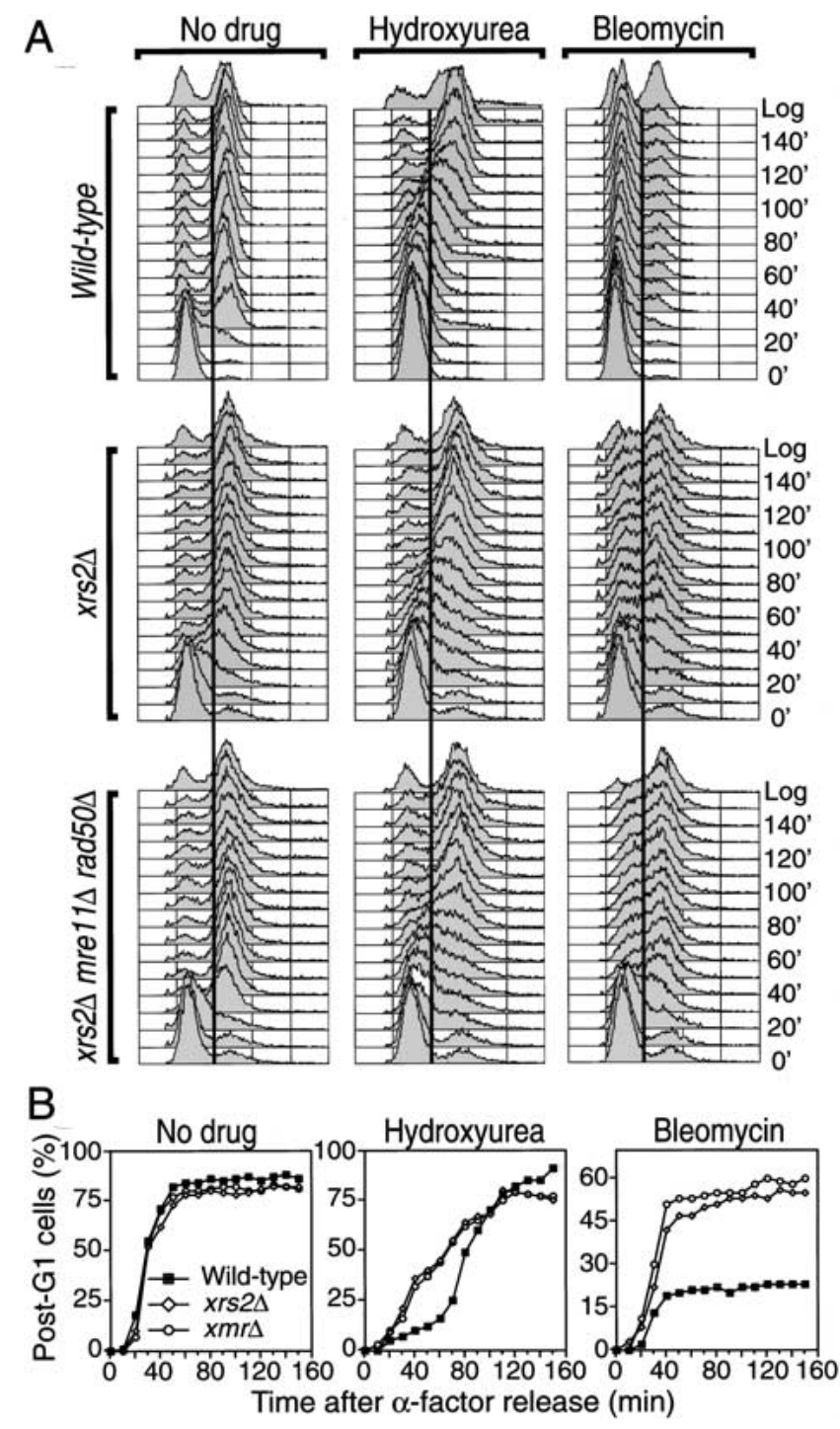

Figure 2. Replicative stress causes premature initiation of DNA synthesis in the absence of a functional Xrs2p complex. (A) $\alpha$-factor-synchronized cells were released from $\mathrm{G}_{1}$ arrest in medium containing nocodazole and no drug (left panels), $40 \mathrm{mM}$ $\mathrm{HU}$ (middle panels), or 35 units/mL bleomycin (right panels), as described in Materials and Methods. Samples were collected at 10-min intervals and analyzed for DNA content by FACS. Yeast strains used were W303-1A (wild-type), DDY004 (xrs2s), and

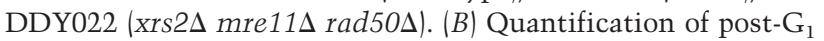
cells. Fraction of cells having a DNA content superior to $G_{1}$ are plotted in function of time below the respective FACS profiles. Numbers are corrected for the presence of cells blocked in $G_{2}$ at time 0 . Typical FACS profiles are shown.

mutants compared with the wild-type strain; DNA replication is initiated about 20 min after release from $G_{1}$ and the bulk of DNA is fully replicated by $50 \mathrm{~min}$ (Fig. $2 \mathrm{~A}, \mathrm{~B}$, left panels). We consistently observe, by FACS analysis and immunofluorescence microscopy, that about $5 \%$ of the population of cells in xrs $2 \Delta$, mre $11 \Delta$, rad50s, and $x m r \Delta$ cultures are irreversibly blocked in a $\mathrm{G}_{2}$-like state (Fig. 2; data not shown) and may represent 
cells that have failed to fully complete the S phase previous to the $\mathrm{G}_{1}$ synchronization.

When wild-type cells are released from $\mathrm{G}_{1}$ arrest in the presence of $40 \mathrm{mM} \mathrm{HU}$, DNA synthesis is delayed by about $50 \mathrm{~min}$ and is completed $\sim 130 \mathrm{~min}$ following release (Fig. 2A,B). In contrast, $x r s 2 \Delta$ and $x m r \Delta$ cells growing in the presence of HU show significant DNA synthesis 30 min following release. For example, $\sim 40 \%$ post- $\mathrm{G}_{1}$ cells are observed at 50 min compared to $12 \%$ for wildtype (numbers are corrected for the presence of cells blocked in $\mathrm{G}_{2}$ at time 0; Fig. 2B). At $60 \mathrm{~min}$, this increases to almost $50 \%$ post $-G_{1}$ cells in $x r s 2 \Delta$ and $x m r \Delta$ cultures compared to $18 \%$ for wild-type yeast. Consistent with this, the elongation of the mitotic spindle in $x r s 2 \Delta$ and $x m r \Delta$ mutants treated with $40 \mathrm{mM}$ HU precedes by at least 30 min the elongation of the mitotic spindle in wild-type cells (see Supplemental Materials). Eventually, however, DNA synthesis in wild-type cells reaches essentially the same levels as in $x r s 2 \Delta$ and $x m r \Delta$ mutants (Fig. 2).

We also examined the contribution of the Xrs2p complex to the DNA damage-induced intra-S phase checkpoint. Cells were synchronized with $\alpha$-factor as before and then released in fresh medium for 5 min to allow exit from $\mathrm{G}_{1}$. Bleomycin, a radiomimetic drug that produces DNA DSBs (Povirk 1996), was then added and samples were collected at intervals. As seen in Figure 2 (right panels), bleomycin induces a strong arrest in wildtype cells; only a small proportion of the culture (maximum of $\sim 20 \%$ of cells) replicate their DNA whereas the majority of cells remains with a $G_{1}$ DNA content throughout the experiment. By contrast, both xrs $2 \Delta$ and $x m r \Delta$ yeast initiate significant DNA replication at 30 min, with $\sim 25 \%-30 \%$; of cells showing post-G G $_{1}$ DNA content, which then increases to $50 \%-60 \%$ of cells from 80 min until the end of the experiment (Fig. 2B). Surprisingly, DNA synthesis is never completed in the xrs2 $\Delta$ and $x m r \Delta$ mutant treated with bleomycin, suggesting that the intra-S phase checkpoint is not completely lost in these mutants (see below). These results are consistent with those obtained with HU and indicate that the $\mathrm{Xrs} 2 \mathrm{p}$ complex is required for the efficient activation of the intra-S phase checkpoint. Essentially identical re-

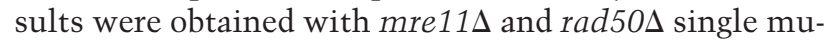
tants, indicating that null mutations in the members of the Xrs2p complex are fully epistatic for their effects on the intra-S phase checkpoint (Figs. 2,3, and see 5C below).

\section{Loss of DNA DSB repair does not impair the intra-S phase checkpoint}

Previous studies have shown that defects in DNA repair genes do not cause deficiencies in the intra-S phase checkpoint or in the DNA replication checkpoint (Allen et al. 1994; Paulovich et al. 1997). However, the members of the budding yeast Xrs2p complex are unique in that they are involved in both nonhomologous end-joining (NHEJ) and HR (for review, see Haber 1998). This raised the possibility that the loss of both NHEJ and HR was responsible for the checkpoint defect observed in the
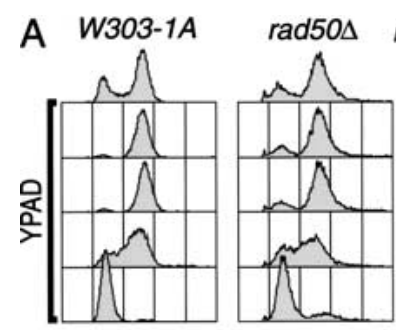

$\operatorname{rad52\Delta }$ yku70 $\Delta$
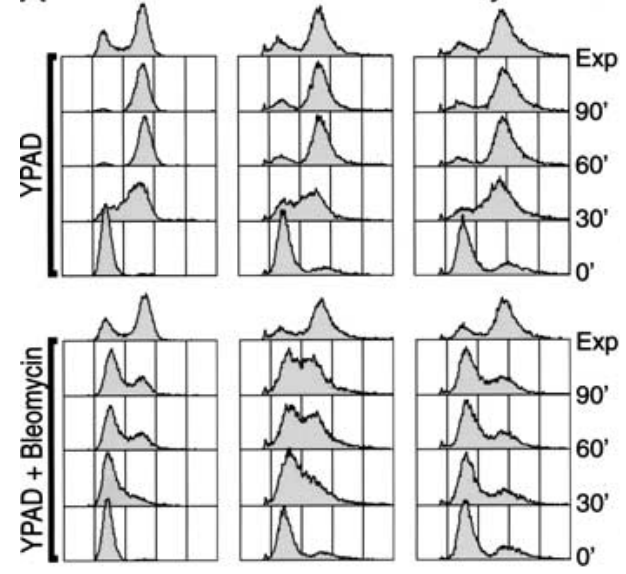

B

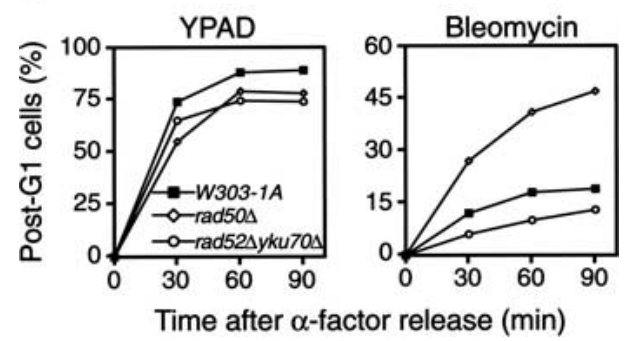

Figure 3. The intra-S phase checkpoint is functional in cells deficient in DNA DSB repair. (A) $\alpha$-factor-synchronized cells were released from $\mathrm{G}_{1}$ arrest in medium containing nocodazole and either no drug (top panels) or 35 units/mL bleomycin (bottom panels). Bleomycin was added $10 \mathrm{~min}$ after the release from $\mathrm{G}_{1}$ and samples were collected at 30-min intervals and analyzed for DNA content by FACS, as described in Materials and Methods. Yeast strains used were W303-1A (wild-type), DDY008

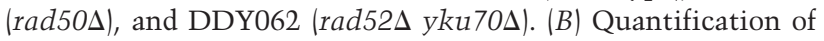
post- $\mathrm{G}_{1}$ cells. Fraction of cells having a DNA content superior to $G_{1}$ are plotted in function of time. Numbers are corrected for the presence of cells blocked in $\mathrm{G}_{2}$ at time 0. Typical FACS profiles are shown.

$x m r$ mutants. To address this issue, we created a mutant

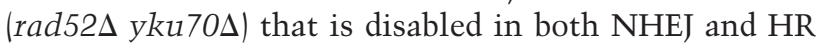
and then compared its bleomycin-induced intra-S phase checkpoint with that of a rad50 0 mutant and wild-type cells. As seen in Figure 3, bleomycin induced an arrest in wild-type cells whereas a significant proportion of rad50 cells engaged in DNA synthesis by $90 \mathrm{~min}$. In contrast, the rad52s yku70s double mutant behaved like wild-type yeast and induced a strong cell cycle arrest during the whole experimental time course. (We consistently observe that a small proportion of rad52 $\mathrm{yku} 70 \Delta$ cells are blocked in a $\mathrm{G}_{2}$-like state even in the presence

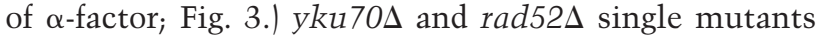
behaved similarly to the double mutant and wild-type cells in this assay (data not shown). Together, these results indicate that loss of NHEJ and HR does not in itself cause an intra-S phase checkpoint deficiency in yeast and that the checkpoint function of the Xrs2p complex is a novel and previously uncharacterized function of this complex. 
The Xrs2p complex is required for efficient checkpoint signaling

To address the potential role(s) of the Xrs2p complex in $S$ phase checkpoint signaling, we evaluated the activation of Rad53p by an in situ assay (ISA assay; Pellicioli et al. 1999). Rad53p is a protein kinase that is activated by the yeast homologs of human ATR and ATM, Mec1p and Tellp, respectively (Sanchez et al. 1996). In the presence of replicative stress, Meclp and Tellp phosphorylate Rad53p, resulting in activation of Rad53p kinase activity and transduction of the checkpoint signal to downstream effectors (Foiani et al. 2000). Wild-type and mutant cells were synchronized in $\mathrm{G}_{1}$ and Rad53p activity was examined by ISA at different times after $G_{1}$ release into medium containing $20 \mathrm{mM}$ or $200 \mathrm{mM} \mathrm{HU}$. For wild-type cells treated with $20 \mathrm{mM} H \mathrm{HU}$, Rad53p activation is detected $30 \mathrm{~min}$ post-release, reaches a peak at about $60 \mathrm{~min}$, and then decreases as cells complete $S$ phase (Fig. 4A). By contrast, xrs $2 \Delta$ and $x r m \Delta$ cells treated
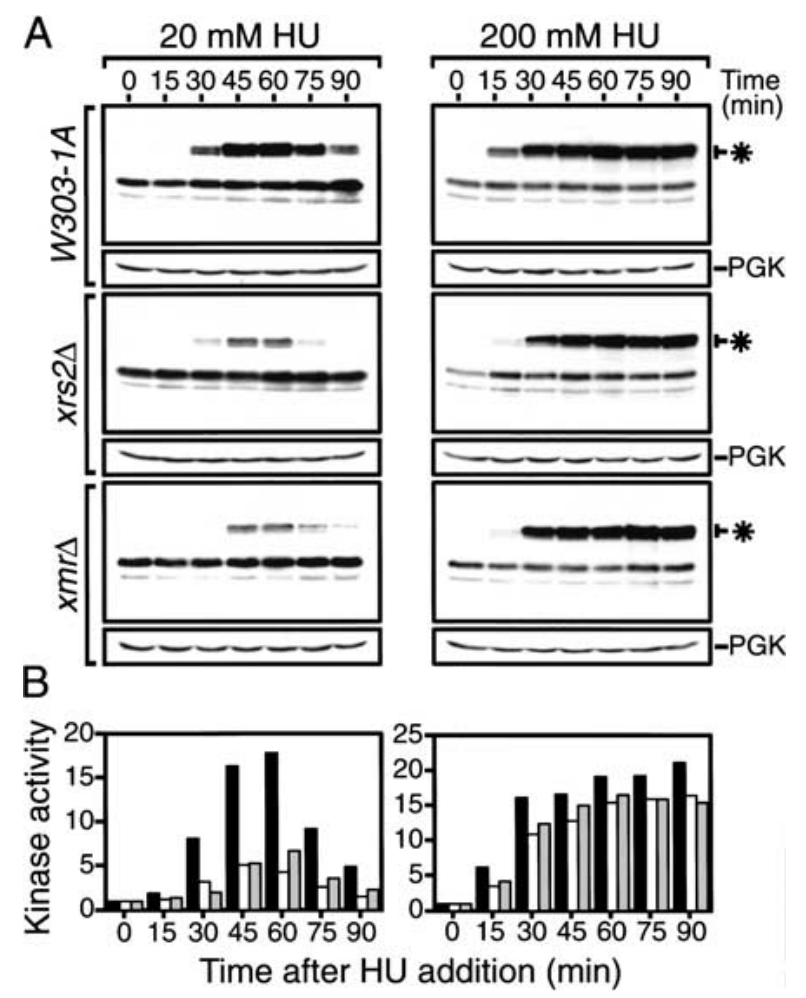

Figure 4. The Xrs2p complex is required for efficient checkpoint signaling. $\mathrm{G}_{1}$-synchronized cells were released from $\alpha$-factor arrest and entered S phase synchronously in the presence either $20 \mathrm{mM}$ (left panels) or $200 \mathrm{mM} \mathrm{HU}$ (right panels). Samples were collected at 15-min intervals and protein extracts were prepared. (A) In situ analysis of Rad53p activity. The position of phosphorylated Rad53p is indicated by a star. Western blot analysis of 3-phosphoglycerate kinase (3-PGK) was performed in parallel (shown below Rad53p ISAs) to confirm equal loading in each lane. $(B)$ Quantification of Rad53p autophosphorylation. Bars represent the relative fold-activation of wild-

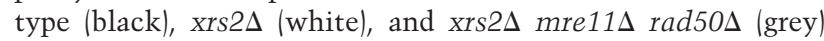
strains. The activity of Rad53p was quantified using Fujifilm BAS-2500. with $20 \mathrm{mM}$ HU show a considerable decrease in the extent of Rad53p activation (Fig. 4A). Indeed, quantification of the results reveals that the maximal Rad53p activity is reduced by about $70 \%-75 \%$ in the mutants compared with the controls (Fig. 4B). Essentially identical results were obtained with mre11 $\Delta$ and rad50 $\Delta$ single mutants, indicating that null mutations in the $X M R$ genes are epistatic for their effects on the Rad53p response (Fig. 5B; data not shown).

The residual Rad53p activity seen in $x m r$ cells treated with $20 \mathrm{mM}$ HU suggests that the signaling pathway can be activated through alternative routes in these mutants. If this is the case, we reasoned that increasing the intensity of the initial signal might bypass a requirement for the Xrs2p complex. To test this, we performed a Rad53p ISA experiment in the presence of $200 \mathrm{mM} \mathrm{HU}$, a concentration that completely blocks DNA replication (Allen et al. 1994). Figure 4A (right panels) shows that wild-type cells treated with $200 \mathrm{mM}$ HU activate Rad53p at the earliest time point after release from $G_{1}$ and that activation persists until the end of the experiment. Similarly, Rad53p is strongly activated in xrs $2 \Delta$ and $x m r \Delta$ mutants in the presence of high concentrations of HU (Fig. 4B). The initiation of the Rad53p response was delayed by about $15 \mathrm{~min}$ in the mutants treated with $200 \mathrm{mM} H U$, but a quantification of the results indicates that the maximal $\operatorname{Rad} 53 \mathrm{p}$ response in these mutants is only marginally decreased (by $10 \%-$ $15 \%$ ) when compared with that of an otherwise isogenic wild-type strain (Fig. 4B, right panel). This result is consistent with the partial restoration of the mitotic spindle elongation delay seen when the $x m r$ mutants are treated with high doses of $\mathrm{HU}$ (data not shown). Activation of Rad53p by bleomycin was also significantly curtailed in $\mathrm{x} m r$ yeast, indicating that the Xrs2p complex is also required for the efficient signaling of DNA DSB (see Supplemental Materials).

\section{Mre11p nuclease activity is required for efficient initiation of the $S$ phase checkpoint}

Because Mre11p is a nuclease, one way that it could potentiate checkpoint-inducing signals in $S$ phase is by generating ssDNA at the sites of stalled replication forks or by otherwise modifying the primary DNA lesion. To test this hypothesis, we evaluated the checkpoint integrity of mre11s cells complemented with centromeric plasmids expressing wild-type Mre11p or derivatives mutated in the nuclease domain. Five Mre11p mutants were generated, four affecting evolutionarily conserved nuclease motifs in the enzyme. Two of these mutations (D56N and H213Y) abrogate the exonuclease and endonuclease activities of Mre11p in vitro (Furuse et al. 1998; Usui et al. 1998). The N113S and Q623X mutations correspond to the two hMre11 mutations found in cancerprone ATLD patients (Stewart et al. 1999). Finally, the P162S mutation affects a proline residue that is conserved in the nuclease domain of all known eukaryotic Mre11 proteins and renders the protein totally inactive at $30^{\circ} \mathrm{C}$ (not at $23^{\circ} \mathrm{C}$, a temperature-sensitive mutant; 
A

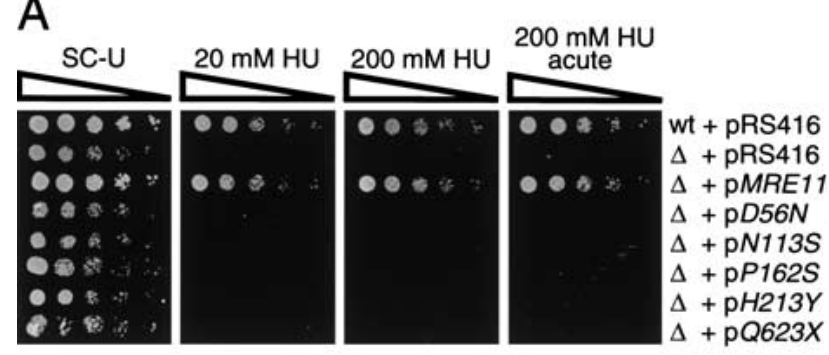

B
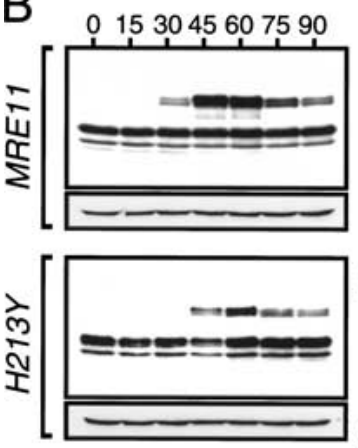

C
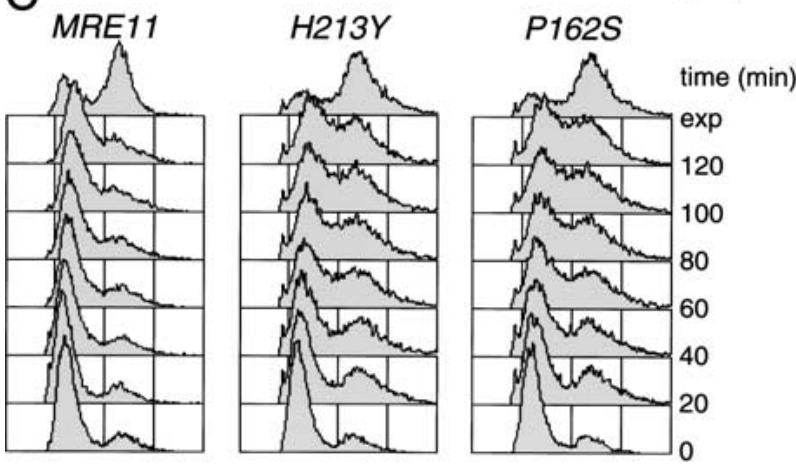

Figure 5. Hypersensitivity of mre11 nuclease mutants to replicative stress. (A) Fivefold serial dilution of mre11s yeast containing single-copy plasmids expressing wildtype Mre11-ProA or various nuclease mutants were plated on SC-uracil containing no drug, $20 \mathrm{mM} \mathrm{HU}$, or $200 \mathrm{mM} \mathrm{HU}$. Exponential cultures were also grown for a further $9 \mathrm{~h}$ in liquid SC-uracil containing $200 \mathrm{mM}$ HU before being washed and plated on SC-uracil plates, as described in Materials and Methods. Wild-type (WT) cells carrying an empty plasmid were included for comparison. $\Delta$ indicates mre11s cells carrying various MRE11 alleles or an empty plasmid. $(B)$ The nuclease activity of Mre11p is required for efficient checkpoint signaling. $\mathrm{G}_{1}$-synchronized mre11s cells expressing wild-type Mre11p and nuclease mutants (H213Y and P162S) were released into a synchronous $\mathrm{S}$ phase in the presence of $20 \mathrm{mM} \mathrm{HU}$. Rad53p activity was evaluated in situ, as described in Figure 4. The lower right panel is a quantification of $\operatorname{Rad} 53 \mathrm{p}$ autophosphorylation; bars represent the relative fold activation of wild-type (black), H213Y mutant (white), and P162S mutant (grey) strains. (C) Mutations in the nuclease domain of Mre11p result in premature initiation of DNA synthesis in the presence of bleomycin. Cells expressing wild-type Mre11p and nuclease mutants (H213Y and P162S) were synchronously released into $\mathrm{S}$ phase in the presence of nocodazole and 25 units/mL bleomycin (added 5 min following release), and processed for FACS analysis.
Johzuka and Ogawa 1995). Figure 5A shows that the ability to grow on $\mathrm{HU}$ is severely compromised by mutations in the nuclease domain of Mre11p. Because growth on HU can be a measure of both DNA repair and checkpoint proficiency (Fig. 1), we performed an HU hypersensitivity (acute treatment) experiment to address the integrity of the checkpoint in these mutants (Allen et al. 1994). Notably, inactivating specific nuclease residues in Mre 1 $1 p$ completely abrogates survival after transient periods of growth in $\mathrm{HU}$ (Fig. 5A).

To characterize further the checkpoint defects associated with the nuclease mutations in Mre11p, we evaluated their effects on Rad53p activation. Because some mutations reduce the stability of Mre11p (D. D'Amours and S.P. Jackson, unpubl.), we selected two mutants (H213Y and P162S) that are stably expressed to wild-type levels for further studies (for expression levels, see Fig. 7B, below). These mutants were released synchronously into $S$ phase in the presence of $20 \mathrm{mM} \mathrm{HU}$ and extracts were prepared at 15 -min intervals. Figure 5B shows that the Rad53p response of the deletion mutant complemented with wild-type MRE11 is essentially identical to that of the wild-type strain (cf. Fig. 4). However, Rad53p activation is significantly impaired in strains expressing the mutant alleles of MRE11 (Fig. 5B). Indeed, Rad53p activation is reduced by $50 \%-60 \%$ in the absence of nuclease activity when the response is at its maximum (45-60 min), which also results in an apparent reduction in the observable duration of Rad53p activation (Fig. 5B).

We also tested the ability of the H213Y and P162S mutants to arrest DNA synthesis in response to bleomy-

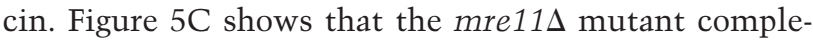
mented with wild-type MRE11 displays normal S phase arrest in response to bleomycin treatment (cf. wild-type responses in Figs. 2 and 5C). In contrast, a significant level of DNA synthesis can be seen with both point mutants, which appear to be particularly affected in their early responses (Fig. 5C). Furthermore, post- $G_{1}$ DNA accumulates gradually during the experiment and corresponds to almost half of the total DNA content (for P162S and $\mathrm{H} 213 \mathrm{Y}$ mutants, $45 \%$ and $42 \%$, respectively at the end of the time course (Fig. 5C). Conversely, the accumulation of post- $\mathrm{G}_{1}$ DNA with wild-type Mre11p is marginal and remains below $22 \%$ of the total DNA content throughout the experiment (Fig. 5C). These results indicate that Mre11p nuclease activity is required to efficiently signal bleomycin-induced damage in $\mathrm{S}$ phase and are consistent with a role of the Xrs2p complex as signal modifier. The checkpoint defects of Mre1lp point mutants are not as strong as those obtained with the deletion mutants, suggesting that there is some nuclease-independent function of the Xrs2p complex in checkpoint activation (Fig. 5B,C). Nevertheless, the phenotype associated with the nuclease mutations in MRE11 is biologically significant because it results in full lethality in response to acute treatment with $\mathrm{HU}$ (Fig. 5A). We have used four mutations each spaced by about 50 residues and covering a region of 150 residues in Mre $11 p$ nuclease domain. Although we cannot exclude secondary effects 
on other aspects of the protein, the above data strongly implicate the nuclease functions of Mre $11 \mathrm{p}$ in the efficient activation of $S$ phase checkpoints.

\section{Xrs2p and Mre11p are phosphorylated after DNA damage in a Tel1p-dependent manner}

Because checkpoint cascades are regulated by phosphorylation (Foiani et al. 2000), we investigated whether the members of the Xrs2p complex are phosphorylated in response to DNA damage and, if so, which kinase(s) is responsible for this. Protein extracts were prepared from exponentially growing cells expressing epitope-tagged Rad50p, Mre11p, or Xrs2p. (These strains were fully complemented for all the xrm phenotypes tested; D. D'Amours and S.P. Jackson, unpubl.). Extracts from cells treated for $1 \mathrm{~h}$ with 4-nitroquinoline-1-oxide (4-NQO), bleomycin, methylmethane sulfonate (MMS), or UV light were resolved by SDS-polyacrylamide gel electrophoresis and subjected to Western blot analysis. Figure 6A shows that Mre11p and Rad50p migrate as single bands in extracts obtained from untreated cultures, whereas Xrs2p appears as a mixture of heterogeneouslymigrating bands, as observed previously (Usui et al. 1998). Upon exposure to 4-NQO or bleomycin, slower migrating forms of Mre11p and Xrs2p are detected (Fig. $6 \mathrm{~A}$; for Xrs2p, the faster migrating bands selectively disappear relative to the slower migrating forms). Interestingly, only marginal enrichment of the slower migrating forms of Mre11p and Xrs2p is seen in samples treated with MMS or UV. No significant retardation of the Rad50p band was observed with any of the DNA damaging agents tested (Fig. 6A). Samples treated with phosphatase contained a single band that corresponds to the faster migrating species in the untreated Mrellp and Xrs2p samples (Fig. 6A, right panel). This confirms that the DNA damage-dependent modification of Mre11p and Xrs2p is due to phosphorylation. (Xrs2p was partly dephosphorylated during the immunoprecipitation procedure, but the slow migrating form is still clearly visible in the untreated sample.) In contrast, Rad50p electrophoretic mobility was unchanged by phosphatase treatment (Fig. 6A).

We next investigated the genetic requirements for Mre11p and Xrs2p phosphorylation. To this end, various checkpoint mutants were transformed with centromeric plasmids expressing tagged Mre11p or Xrs2p and their ability to phosphorylate these proteins was evaluated. Perhaps surprisingly, the levels of phosphorylation of both Xrs2p and Mre11p remained unchanged in rad9s,

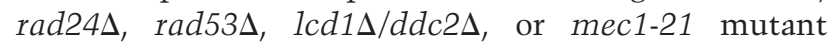
strains (Fig. 6B, see legend for details), which represent the main epistasis groups known to be involved in checkpoint responses (for review, see Foiani et al. 2000). In marked contrast, DNA damage-dependent phosphorylation of Xrs2p was no longer detected in tel1s or tel1s mec1-21 mutants (Fig. 6B). Similarly, the absence of Tellp resulted in a significant decrease in the phosphorylation of Mre11p and the residual phosphorylation was eliminated by an additional mutation in MEC1. Mre11p

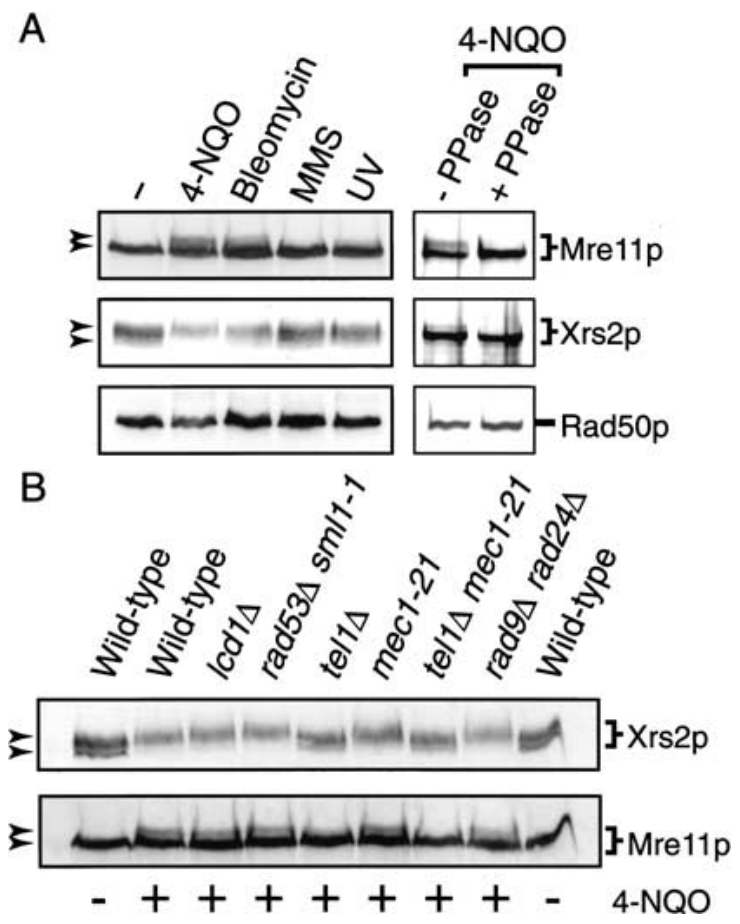

Figure 6. Xrs2p and Mre11p are phosphorylated in response to DNA damage. (A) Exponentially growing cultures of yeast expressing Mre11-13Myc, Xrs2-13Myc and Rad50-3FLAG were analyzed for protein phosphorylation in response to DNA damage (left panels). Cells were untreated (-) or treated with either 4-NQO $(25 \mu \mathrm{M})$, bleomycin (350 units/mL), MMS $(0.02 \%)$, or $\mathrm{UV}\left(60 \mathrm{~J} / \mathrm{m}^{2}\right)$. Arrows indicate the position of the phosphorylated and unphosphorylated bands (left). For dephosphorylation experiments (right panels), Mre11p, Xrs2p, and Rad50p were immunoprecipitated from soluble extracts of yeast treated with 4-NQO. Half of each immunoprecipitate was dephosphorylated with $\lambda$ phosphatase; the remaining half was mock treated. $(B)$ Genetic requirements for phosphorylation of Mrellp and Xrs2p. Exponential cultures of various checkpoint mutants expressing Myc-tagged Xrs2p or Mre11p were treated with 4-NQO $(25 \mu \mathrm{M})$. Untreated $(-)$ and treated $(+)$ wild-type cultures were also included as controls. Protein extracts were prepared $1 \mathrm{~h}$ after the addition of 4-NQO and analyzed by Western blotting. Arrows indicate the position of the basal and phosphorylated bands (left). Mutant strains are as follows: tel1s (Y662), mec121 (Y663), tel1s mec1-21 (Y664), rad53s sml1-1 (U960-5C), rad9 $\mathrm{rad} 24 \Delta$ and $1 c d 1 \Delta$. The mec1-21 allele used here is a hypomorphic allele that does not require a second site mutation for the suppression of mec1s-associated lethality (Desany et al. 1998). Although it is not known whether this allele is completely defective for checkpoint functions, the similar results obtained with the $1 c d 1 \Delta / d d c 2 \Delta$ mutant (which is fully epistatic with MEC1; Rouse and Jackson 2000) and the mec1-21 mutant supports the view that we observe the full effect of the loss of Meclp in our phosphorylation assay.

and Xrs2p are the only proteins so far shown to be preferentially phosphorylated in a Tellp-dependent manner during the cellular response to DNA damage.

\section{TEL1 and XRS2 are in the same epistasis group}

A role for Tellp in checkpoint regulation has been inferred from the ability of overexpressed Tellp to sup- 
press the DNA damage sensitivity of a Meclp-deficient strain and from the fact that a tel1 mutation exacerbates the HU and DNA damage sensitivity of a mec1 mutant (Morrow et al. 1995). Accordingly, we have observed that Tellp-deficient yeast have a weak intra-S phase checkpoint defect and that the loss of the TEL1 gene in a mec121 background enhances the checkpoint defect of this strain (see Supplemental Materials). Taken together with the above data, these observations suggest that TEL1 might be in the same epistasis group as the products of the $X R M$ genes. To test this idea, we generated strains deficient in the XRS2, TEL1, MEC1, and RAD53 genes as single or combination mutants and then examined their sensitivity to low doses of HU. Because some combinations of mutation in a mec1s background result in a senescence phenotype, we isolated survivor clones of these strains that grow at a rate comparable to that of other mutants (Ritchie and Petes 2000). This allowed us to perform a semi-quantitative analysis of the HU sensitivity of each mutant.

Figure 7A shows the results of the epistatic analysis. The point at which the single mutants become significantly sensitive to $\mathrm{HU}$ is as follows: $x r s 2 \Delta, 4 \mathrm{mM}$; rad53 $\Delta, 2-4 \mathrm{mM}$; tel1 $\Delta$, not sensitive; mec1s, $2 \mathrm{mM}$ (Fig. 7A). In comparison, all the double mutants, except the tel1 $x$ xs $2 \Delta$ strain, became significantly sensitive to HU at a concentration of $1 \mathrm{mM}$. Interestingly, the sensitivity of the xrs $2 \Delta$ mec1s mutant is not significantly exacerbated by the addition of a tel1 $\Delta$ mutation (both $x r s 2 \Delta$ mec1s and xrs $2 \Delta$ mec1s tel1 $\Delta$ cells are sensitive to the same extent at $1 \mathrm{mM} \mathrm{HU),} \mathrm{which} \mathrm{indicates} \mathrm{that} \mathrm{xrs} 2 \Delta$ and tel1 $\Delta$ mutations are epistatic. Indeed, in this system, combining mec1s and tel1s mutations /which exacerbates the mec1s phenotype) serves as a positive control for a Tellp-specific effect because Tellp-deficient mutants have no HU sensitivity on their own (Fig. 7A; Morrow et al. 1995). These results are consistent with xrs2 $\Delta$ and tel1 $\Delta$ mutations working epistatically in regard to a chromosome rearrangement phenotype (Myung et al.
2001). Interestingly, we could not obtain any viable mec1s xrs $2 \Delta$ spores in the absence of SML1 mutations (either $s m l 1 \Delta$ or sml1-1 alleles; data not shown) during the construction of our double mutants. This result indicates that loss of XRS2 does not suppress the lethality of mec1s (by increasing the levels of dNTPs) and makes it unlikely that the faster rates of DNA replication that we see in Figure 2 are due to altered dNTPs pools.

\section{Tel1p-dependent phosphorylation of Mre11p is a feedback response to checkpoint activation}

Our results are consistent with a model in which the Xrs2p complex acts with Tellp at the level of the DNA damage to activate the checkpoint. If the nuclease activity of Mre $11 \mathrm{p}$ is required to modify the initial damage so that it can activate the checkpoint more efficiently, we would expect that checkpoint kinases, including Tellp, would not be fully activated in strains expressing nuclease mutants of Mre11p. Alternatively, if the nuclease activity of Mre11p is not required for Tellp and Mec1p activation, we would expect that the nuclease mutants of Mre11p would be phosphorylated as efficiently as the wild-type enzyme. To address these two possibilities, we tested whether the nuclease activity of Mre11p is required for its Tellp-dependent phosphorylation. Yeast expressing either wild-type or Mre11p mutants affected in the nuclease domain (H213Y and P162S) were grown to early log-phase, treated with 4-NQO, and extracts were prepared at $15 \mathrm{~min}$-intervals to analyze the kinetics of Mre11p phosphorylation. Figure 7B shows that a weak phosphorylation of wild-type Mre11p can be seen early on during the experiment, which increases significantly at $30 \mathrm{~min}$ and reaches a maximal level $60 \mathrm{~min}$ after the addition of the DNA-damaging drug. In contrast, no phosphorylation is seen with either Mre11p mutant at any time point during the experiment (Fig. 7B). Taken together with the current literature (Lee et al. 1998; Pellicioli et al. 2001), our results strongly suggest that the
A

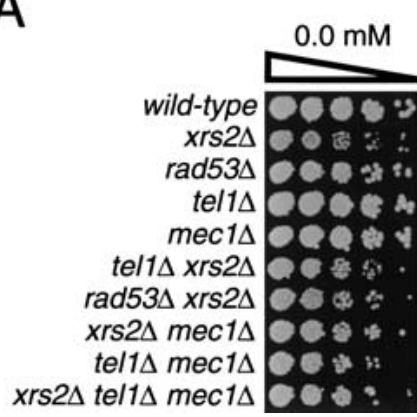

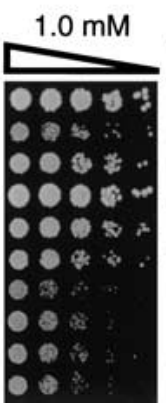
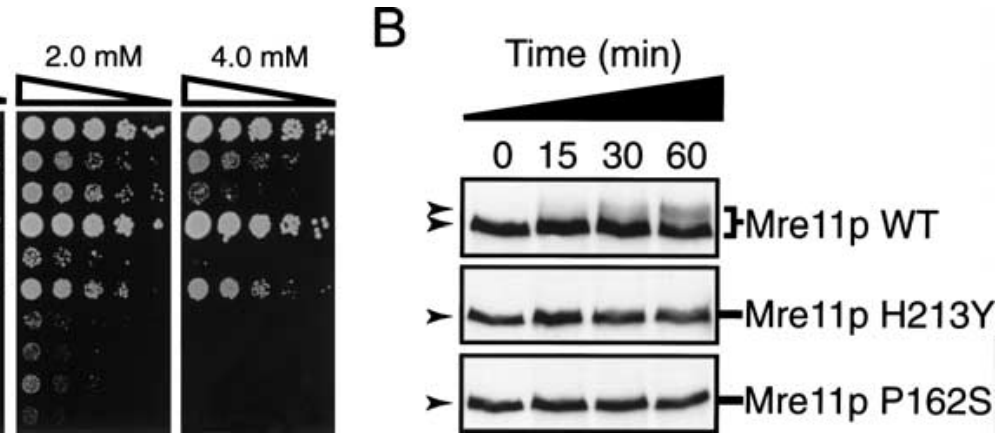

Figure 7. Functional and epistatic interactions between the Xrs2p complex and Tellp. $(A)$ HU sensitivity of various mutants affected in the XRS2, RAD53, TEL1, and MEC1 genes. Fivefold serial dilution of yeast cultures were plated on YPAD medium containing low concentrations of $\mathrm{HU}$. Survival was scored after $2-3 \mathrm{~d}$ of growth at $30^{\circ} \mathrm{C}$. (We consistently observe that a tel1s mutation partially suppresses the slow growth phenotype associated with a xrs $2 \Delta$ mutation, possibly because Tellp is inappropriately activated in the absence of Xrs2p.) Yeast genotypes are on the left side of the panels. All the strains tested have a sm11-1 mutation. (B) Nuclease mutants of Mre11p are not phosphorylated in response to DNA damage. Exponential cultures of mre11 $\Delta$ mutants expressing wild-type or nuclease-defective (H213Y and P162S) Mre11-ProA were damaged with 4-NQO (25 $\mu \mathrm{M})$ and samples were taken at timed intervals. Protein extracts and Western blot analysis were performed as described in Figure 6. 
nuclease activity of Mre11p is required for the efficient activation of the checkpoint kinases and is consistent with the view that the phosphorylation of Mre11p is a feedback response from the checkpoint signaling pathway.

\section{Discussion}

The Xrs $2 p$ complex is required for the initiation of $S$ phase checkpoints

Here, we describe a previously uncharacterized role for the Xrs2p complex in checkpoint regulation during $S$ phase. We show that yeast lacking a functional Xrs2p complex are defective in both the HU-induced checkpoint and the bleomycin-induced intra-S phase checkpoint. Specifically, we see that Xrs2p-deficient yeast experiencing replicative stress initiate DNA synthesis earlier than wild-type cells, are unable to inhibit the elongation of their mitotic spindle, and fail to efficiently activate Rad53p, a central checkpoint regulator. The role of the Xrs2p complex in checkpoint regulation does not appear to reflect its role in NHEJ and HR because loss of

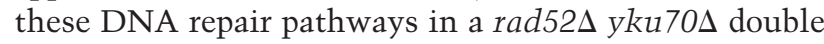
mutant does not impair the intra-S phase checkpoint. Taken together, our results indicate that the role of the Xrs2p complex in S phase arrest is a novel and previously uncharacterized function of this complex.

It is noteworthy that a specific defect in the initiation of the intra-S phase checkpoint in $x m r$ mutants results in severe lethality in the presence of replicative stress (Fig. 1). This phenotype is consistent with the results of Desany et al. (1998) who have shown that the inability to respond to replicative stress in the rad53 mutant results in an irreparable catastrophe during DNA replication, possibly due to collapsed replication forks. Our results indicate that Rad53p needs to be fully activated very early during replicative stress to ensure survival, and that later activation of the kinase, as seen in $\mathrm{xmr}$ mutants, is not sufficient to restore viability. It is likely that the lethal events in $x m r$ and rad53 mutants experiencing replicative stress are the same because $x m r \Delta$ cells fail to properly activate Rad53p.

\section{The Tel1p-Xrs2p signal transduction pathway is conserved from yeast to humans}

Cells isolated from AT patients show similar cellular phenotypes to NBS and ATLD cells (Petrini 2000). This led to the early suggestion that the products of the ATM and NBS1 genes would be involved in the same processes during the response to DNA damage. This assumption was confirmed recently when it was shown that ATM phosphorylates Nbs1 in response to DNA damage and that this is necessary to enforce the intra-S phase checkpoint (for review, see Michelson and Weinert 2000). Interestingly, previous studies have shown that the yeast homolog of ATM, Tellp, has only a minor role in the DNA damage response. Indeed, Tellp seems to be necessary for DNA damage resistance only in the absence of the predominant kinase Meclp (Morrow et al. 1995). By contrast, we show that Tellp is required for the effective phosphorylation of Mre11p and Xrs2p in vivo, and that Meclp only plays an accessory role in these events. This is the first time that a primary dependence on Tellp has been demonstrated for the phosphorylation of checkpoint proteins and strongly suggests that the fundamental mechanisms of the signaling pathway are conserved from yeast to humans.

It is important to note that there is not a simple causative link between checkpoint defects and DNA damage sensitivity. This is clearly evidenced by the behavior of chk1 mutant in yeast (Sanchez et al. 1999), by the identification of checkpoint-deficient alleles of MEC1 that are not DNA damage sensitive (Weinert et al. 1994), by the general lack of DNA damage sensitivity of mammalian $\mathrm{p} 53^{-/-}$cell lines, and by the fact the DNA damage sensitivity and checkpoint defect of AT cells can be dissociated (for review, see Jeggo et al. 1998). In light of this, it is not necessarily surprising that Tellp could be involved in important checkpoint responses and yet tel1 mutant strains are not markedly hypersensitive to HU or DNA damage.

Interestingly, the phosphorylation of Mre11p by Tellp appears to be dependent on the nucleolytic activity of the Xrs2p complex, suggesting that Mre11p phosphorylation is a feedback response to Tellp activation. It is tempting to speculate that this phosphorylation alters the biochemical properties of Mrel1p and redirects the Xrs2p complex toward other activities (such as DNA repair) once the intra-S phase checkpoint has been triggered. There is some evidence in humans for a biphasic redistribution of the Nbs1 complex during the DNA damage response, which suggests that the Nbs1 complex has two distinct functions that are temporally separated (Carney et al. 1998). It would perhaps make sense if the Nbs1/Xrs2p complex would need to activate the intra-S phase checkpoint first so that the cell cycle is slowed and time is provided to repair DNA damage. Mre11p phosphorylation might then act as a switch to commit the Xrs2p complex to DNA repair activities following checkpoint activation. Clearly, careful biochemical studies will be required to address these important issues.

\section{The Xrs $2 p$ complex as a signal-modifier during $S$ phase}

The identity of the DNA damage sensors and the nature of the process(es) leading to DNA damage recognition during checkpoint activation are currently unclear. DNA can be damaged in several ways, and each type of lesion has its own typical structure and requirements for detection (for review, see Friedberg et al. 1995). To address the structural diversity of DNA lesions, the process of DNA repair utilizes several distinct pathways, each of which is concerned with a class of structurally similar lesions. Perhaps surprisingly, however, current data suggest that DNA damage activates a common set of checkpoint proteins independently of the nature of the DNA lesion (Foiani et al. 2000). This indicates either that there is a multitude of DNA damage sensors acting in checkpoint pathways or that it is not the primary lesion itself that is detected but a common intermediate resulting 
from the processing of the damage. This latter mechanism would seem to be structurally less demanding for the cell and is attractive because the common intermediate could be easily provided by signal modifiers associated with DNA repair or DNA replication processes. Accordingly, it has been shown that irreparable UV lesions are only efficiently detected during S phase in both human and yeast cells, which indicates that the initial damage is processed to a signaling-competent state during DNA replication (Nelson and Kastan 1994; Neecke et al. 1999). This conclusion is also supported by recent results indicating that alkylation and UV-induced lesions are converted to DSBs during $S$ phase (Galli and Schiestl 1999). Whether DSBs can induce the checkpoint response directly or have to be processed first is unknown. However, it is tempting to speculate that DSBs may serve as ideal intermediates for exonucleases to produce ssDNA, a structure that has been shown to be a potent activator of checkpoint responses (Garvik et al. 1995; Lydall and Weinert 1995; Lee et al. 1998).

Mre11p is a strong candidate for this nuclease activity because it has already been shown to be required for the formation of ssDNA regions in vivo at meiotic DSBs and during mating-type switching (Lee et al. 1998; Usui et al. 1998). Furthermore, our finding that the Xrs2p complex is required to signal the presence of low levels of DNA damage to the checkpoint machinery, and that this role can be partly bypassed by increasing the levels of DNAdamaging agent, suggests that the Xrs2p complex potentiates the checkpoint-inducing properties of DNA damage. The simplest model to accommodate these observations is that Mre $11 \mathrm{p}$ nuclease processes DNA DSBs into checkpoint-activating lesions during S phase. Evidence supporting this interpretation has also been obtained recently from the work of Lee et al. (1998) and Pellicioli et al. (2001) who have shown that cells deficient in Mre11p adapt more readily to the presence of a single HO-induced DSB than wild-type cells. Their interpretation of the data is that Mre $11 \mathrm{p}$ is normally required to produce the ssDNA required to maintain the checkpoint and that in the absence of this signal, cells abrogate the checkpoint response and exit cell cycle arrest (adaptation). However, it is notable that the nuclease activity of Mre11p in vitro is of the opposite polarity $\left(3^{\prime} \rightarrow 5^{\prime}\right)$ to the polarity of HO-induced DSB resection in vivo $\left(5^{\prime} \rightarrow 3^{\prime}\right)$. Because of this discrepency and because MRE11 deletion mutants have been used in previous studies, there is still some debate as to whether Mre11p is directly responsible for the nucleolytic degradation of DNA DSBs or whether it is required to activate a second nuclease that is then responsible for the nucleolytic degradation.

Our analyses of Mre11p nuclease mutants address this issue and strongly suggest that Mre11p nuclease activity is directly responsible for creating the checkpoint-inducing signal. All the exonuclease mutants of Mre11p we have tested so far are highly defective in the intra-S phase checkpoint, are deficient in Rad53p activation, show premature DNA synthesis, and are defective in Tellp-dependent phosphorylation. The importance of Mre11p nuclease activity for the activation of the intra-S phase checkpoint is reinforced by the fact that a mutation affecting a conserved residue in the nuclease domain of hMre11 causes RDS in ATLD patients (Stewart et al. 1999; see discussion in Rhind and Russell 2000). Although it is difficult to formally exclude potential secondary effects associated with nuclease mutations, the available data strongly suggest that the Xrs2p complex acts as a signal modifier to potentiate the checkpoint-inducing properties of primary DNA lesions during S phase.

\section{Materials and methods}

\section{Plasmid and strain construction}

Yeast strains with complete deletion of the coding sequence of XRS2, MRE11, RAD50, RAD51, RAD52, or TEL1 genes were constructed according to Baudin et al. (1993) in the original W303-1A background (Table 1). Construction of multiple mutant strains was performed by mating the appropriate single mutants. Genotypes were confirmed by PCR and by complementation with single-copy plasmids (pRS416) carrying the promoter, full-length coding sequence and transcription terminator of the deleted gene. pRS416-based plasmids expressing Xrs213Myc, Mre11-13Myc, Mre11-ProA (Protein A), and Rad503FLAG were created by subcloning the appropriate tags (Longtine et al. 1998) in frame with the last codon of the genes. All plasmids were shown to be fully functional by complementation of the appropriate mutant strains. Mutagenesis of the nuclease domain of Mre11-ProA was performed with the QuickChange mutagenesis kit (Stratagene).

\section{$H U$ and bleomycin sensitivity assays}

For growth on solid medium containing HU or bleomycin, saturated cultures were diluted to $\mathrm{A}_{600}$ of 0.3 and fivefold dilution series were spotted on plates and grown at $30^{\circ} \mathrm{C}$ for $2 \mathrm{~d}(>40 \mathrm{mM}$ HU or bleomycin) or $4 \mathrm{~d}$ (200 mM HU). Stock solutions of bleomycin (Bleo-Kyowa) were freshly prepared before each experiment at a concentration of 15,000 international units/mL in water. To test for HU hypersensitivity (acute treatment), saturated cultures were diluted to $\mathrm{A}_{600}$ of 0.3 in liquid YPAD (or in $\mathrm{SC}$-uracil for mre11 nuclease mutants) and grown for $1.5 \mathrm{~h}$ at $30^{\circ} \mathrm{C}$. HU was then added to $200 \mathrm{mM}$ and cultures were incubated for $9 \mathrm{~h}$ with shaking at $30^{\circ} \mathrm{C}$. Cells were washed with water, diluted to an $\mathrm{A}_{600}$ of 0.3 , and fivefold dilution series were spotted on YPAD or SC-uracil plates. Survival was scored after 2-3 d.

\section{Analysis of the S-phase checkpoint}

FACS analysis and Rad53p activation assays were performed with synchronized cells as follows. Early log cultures were synchronized in $\mathrm{G}_{1}$ with $5 \mu \mathrm{g} / \mathrm{mL} \alpha$-factor for $1.5 \mathrm{~h}$. After confirming the efficiency of the arrest by light microscopy (>95\%), cells were extensively washed to eliminate $\alpha$-factor and then released in liquid YPAD. For HU experiments, the drug was added at the onset of the release at a final concentration of $20 \mathrm{mM}, 40 \mathrm{mM}$, or $200 \mathrm{mM}$, as described in figure legends. For bleomycin, the drug was added after 5-10 min of growth to allow the cells to enter S phase. Samples were taken at various time points and processed for the following assays. $S$ phase progression was monitored by FACS on a Becton Dickinson FACSort cytometer equipped with the CELLQuest software, as previously described (Paulovich et al. 1997), except that nocodazole was added to 15 $\mu \mathrm{g} / \mathrm{mL}$ when releasing cells to prevent progression to $G_{1}$. In situ Rad53p kinase assays (ISA) were performed according to Pellicioli et al. (1999). In addition, extracts were probed with anti- 
Table 1. Yeast strains used in this study

\begin{tabular}{|c|c|c|}
\hline Strain & Genotype & Constructed by \\
\hline W303-1A & Mata ade2-1 can1-100 his3-11,15 leu2-3,112 rad5-535 trp1-1 ura3-1 & R. Rothstein \\
\hline U960-5C & W303-1A, sml1-1 rad53::HIS3 & R. Rothstein \\
\hline Y661 & Mata ade2-1 can1-100 his3-11,15 leu2-3,112 rad5-535 trp1-1 ura3-1 & S. Elledge \\
\hline Y 662 & Y 661, tel1::HIS3 & S. Elledge \\
\hline Y663 & Y661, mec1-21 & S. Elledge \\
\hline Y664 & Y661, tel1::HIS3, mec1-21 & S. Elledge \\
\hline $\operatorname{lcd} 1 \Delta$ & W303-1A, 1cd1::LEU2 & J. Rouse \\
\hline $\operatorname{rad} 9 \Delta \operatorname{rad} 24 \Delta$ & W303-1A, rad9::HIS3 rad24::TRP1 & D. Durocher \\
\hline hdf1 & W303-1A, yku70::LEU2 & H. Feldmann \\
\hline DDY004 & W303-1A, xrs2::LEU2 & This study \\
\hline DDY006 & W303-1A, mre11::HIS3 & This study \\
\hline DDY008 & W303-1A, rad50:TRP1 & This study \\
\hline DDY022 & W303-1A, xrs2::LEU2 mre11::HIS3 rad50::TRP1 & This study \\
\hline DDY029 & W303-1A, rad9::URA3 & This study \\
\hline DDY035 & W303-1A, sm11-1 xrs2::LEU2 rad53::HIS3 & This study \\
\hline DDY042 & W303-1A, rad51::HIS3 & This study \\
\hline DDY050 & W303-1A, sml1-1 & This study \\
\hline DDY051 & W303-1A, sm11-1 xrs2::LEU2 & This study \\
\hline DDY052 & W303-1A, sml1-1 tel1::HIS3 & This study \\
\hline DDY053 & W303-1A, sm11-1 mec1::TRP1 & This study \\
\hline DDY056 & W303-1A, sml1-1 xrs2::LEU2 tel1::HIS3 & This study \\
\hline DDY062 & W303-1A, yku70::LEU2 rad52::TRP1 & This study \\
\hline DDY063 & W303-1A, sm11-1 mec1::TRP1 xrs2::LEU2 & This study \\
\hline DDY064 & W303-1A, sml1-1 mec1::TRP1 tel1::HIS3 & This study \\
\hline DDY065 & W303-1A, sm11-1 mec1::TRP1 xrs2::LEU2 tel1::HIS3 & This study \\
\hline
\end{tabular}

PGK (22C5-D8; Molecular Probes) monoclonal antibody to confirm equal loading.

\section{Phosphorylation analysis}

Exponentially growing cells expressing tagged proteins were treated with DNA damaging agents in liquid SC-uracil medium. Cells were treated with $25 \mu \mathrm{M}$ 4-NQO, 350 units/mL bleomycin, or $0.02 \%$ MMS for $1 \mathrm{~h}$. For UV treatment, cells were exposed to $60 \mathrm{~J} / \mathrm{m}^{2} \mathrm{UV}$ and left to recover for $1 \mathrm{~h}$. Trichloroacetic acid extracts were prepared as described by Pellicioli et al. (1999) and proteins were resolved by $8 \%$ SDS-PAGE in gels containing a 150:1 ratio of acrylamide to bis-acrylamide. Western blots were performed with anti-Myc-9E10 and anti-FLAG-M2 monoclonal antibodies, as described (Pellicioli et al. 1999). Primary antibodies and Mre11-ProA were detected with HRP-conjugated rabbit anti-mouse IgG antibody (Dako). Soluble extract preparation and dephosphorylation were performed as described by Pellicioli et al. (1999).

\section{Acknowledgments}

We thank all members of the Jackson laboratory, especially John Rouse and Daniel Durocher, for helpful discussions. We are also grateful to S. Elledge, R. Rothstein, and H. Feldmann for providing strains and to $\mathrm{A}$. Bardin for instructions on the spindle immunofluorescence procedure. D.D. is supported by scholarships from the Conseil de Recherche en Science Naturelle et en Génie (CRSNG) du Canada, from the Fond pour la Formation de Chercheurs et l'Aide à la Recherche du Québec (Fonds FCAR), and from the Cancer Research Campaign. This work was funded by the Cancer Research Campaign.

The publication costs of this article were defrayed in part by payment of page charges. This article must therefore be hereby marked "advertisement" in accordance with 18 USC section 1734 solely to indicate this fact.

\section{References}

Alani, E., Subbiah, S., and Kleckner, N. 1989. The yeast RAD50 gene encodes a predicted $153-\mathrm{kD}$ protein containing a purine nucleotide-binding domain and two large heptad-repeat regions. Genetics 122: 47-57.

Allen, J.B., Zhou, Z., Siede, W., Friedberg, E.C., and Elledge, S.J. 1994. The Sad1/Rad53 protein kinase controls multiple checkpoints and DNA damage-induced transcription in yeast. Genes \& Dev. 8: 2401-2415.

Baudin, A., Ozier-Kalogeropoulos, O., Denouel, A., Lacroute, F., and Cullin, C. 1993. A simple and efficient method for direct gene deletion in Saccharomyces cerevisiae. Nucleic Acids Res. 21: 3329-3330.

Carney, J.P., Maser, R.S., Olivares, H., Davis, E.M., LeBeau, M., Yates, J.R., Hays, L., Morgan, W.F., and Petrini, J.H.J. 1998. The hMre11/hRad50 protein complex and Nijmegen breakage syndrome: Linkage of double strand break repair to the cellular DNA damage response. Cell 93: 477-486.

Desany, B.A., Alcasabas, A.A., Bachant, J.B., and Elledge, S.J. 1998. Recovery from DNA replicational stress is the essential function of the S phase checkpoint pathway. Genes \& Dev. 12: 2956-2970.

Foiani, M., Pellicioli, A., Lopes, M., Lucca, C., Ferrari, M., Liberi, G., Muzi Falconi, M., and Plevani, P. 2000. DNA damage checkpoints and DNA replication controls in Saccharomyces cerevisiae. Mutat. Res. 451: 187-196.

Friedberg, E.C., Walker, G.C., and Siede, W. 1995. DNA repair and mutagenesis. ASM Press, Washington, DC.

Furuse, M., Nagase, Y., Tsubouchi, H., Murakami-Murofushi, K., Shibata, T., and Ohta, K. 1998. Distinct roles of two separable in vitro activities of yeast Mre11 in mitotic and meiotic recombination. EMBO T. 17: 6412-6425.

Galli, A. and Schiestl, R.H. 1999. Cell division transforms mutagenic lesions into deletion-recombinagenic lesions in yeast cells. Mutat. Res. 429: 13-26. 
Garvik, B., Carson, M., and Hartwell, L. 1995. Single-stranded DNA arising at telomeres in cdc13 mutants may constitute a specific signal for the RAD9 checkpoint. Mol. Cell. Biol. 15: 6128-6138.

Haber, J.E. 1998. The many interfaces of Mre11. Cell 95: 583 586.

Jeggo, P.A., Carr, A.M., and Lehmann, A.R. 1998. Splitting the ATM: Distinct repair and checkpoint defects in ataxia telangiectasia. Trends Genet. 14: 312-316.

Johzuka, K. and Ogawa, H. 1995. Interaction of Mre11 and Rad50: Two proteins required for DNA repair and meiosisspecific double-strand break formation in Saccharomyces cerevisiae. Genetics 139: 1521-1532.

Kironmai, K.M. and Muniyappa, K. 1997. Alteration of telo meric sequences and senescence caused by mutations in RAD50 of Saccharomyces cerevisiae. Genes Cells 2: 443-455.

Lee, S.E., Moore, J.K., Holmes, A., Umezu, K., Kolodner, R.D., and Haber, J.E. 1998. Saccharomyces Ku70, Mre11/Rad50, and RPA proteins regulate adaptation to G2/M arrest after DNA damage. Cell 94: 399-409.

Longtine, M.S., McKenzie, III, A., Demarini, D.J., Shah, N.G., Wach, A., Brachat, A., Philippsen, P., and Pringle, J.R. 1998. Additional modules for versatile and economical PCR-based gene deletion and modification in Saccharomyces cerevisiae. Yeast 14: 953-961.

Luo, G.B., Yao, M.S., Bender, C.F., Mills, M., Bladl, A.R., Bradley, A., and Petrini, J.H.J. 1999. Disruption of mRad50 causes embryonic stem cell lethality, abnormal embryonic development, and sensitivity to ionizing radiation. Proc. Natl Acad. Sci. 96: 7376-7381.

Lydall, D. and Weinert, T 1995. Yeast checkpoint genes in DNA damage processing: Implications for repair and arrest. Science 270: 1488-1491.

Merrill, B.J. and Holm, C. 1999. A requirement for recombinational repair in Saccharomyces cerevisiae is caused by DNA replication defects of mecl mutants. Genetics 153: 595-605.

Michelson, R.J. and Weinert, T. 2000. Closing the gaps among a web of DNA repair disorders. Bioessays 22: 966-969.

Morrow, D.M., Morrow, M., Tagle, D.A., Shiloh, Y., Collins, F.S., and Hieter, P. 1995. Tel1, an S. cerevisiae homolog of the human gene mutated in Ataxia telangiectasia, is functionally related to the yeast checkpoint gene MEC1. Cell 82: 831-840.

Myung, K., Datta, A., and Kolodner, R.D. 2001. Suppression of spontaneous chromosomal rearrangements by $\mathrm{S}$ phase checkpoint functions in Saccharomyces cerevisiae. Cell 104: 397-408.

Neecke, H., Lucchini, G., and Longhese, M.P. 1999. Cell cycle progression in the presence of irreparable DNA damage is controlled by a Mec1- and Rad53-dependent checkpoint in budding yeast. EMBO J. 18: 4485-4497.

Nelson, W.G. and Kastan, M.B. 1994. DNA strand breaks: The DNA template alterations that trigger p53-dependent DNA damage response pathways. Mol. Cell. Biol. 14: 1815-1823.

Painter, R.B. and Young, B.R. 1980. Radiosensitivity in ataxiatelangiectasia: A new explanation. Proc. Natl Acad. Sci. 77: 7315-7317.

Paulovich, A.G., Margulies, R.U., Garvik, B.M., and Hartwell, L.H. 1997. RAD9, RAD17, and RAD24 are required for S phase regulation in Saccharomyces cerevisiae in response to DNA damage. Genetics 145: 45-62.

Pellicioli, A., Lucca, C., Liberi, G., Marini, F., Lopes, M., Plevani, P., Romano, A., DiFiore, P.P., and Foiani, M. 1999. Activation of Rad53 kinase in response to DNA damage and its effect in modulating phosphorylation of the lagging strand DNA polymerase. EMBO T. 18: 6561-6572.
Pellicioli, A., Lee, S.E., Lucca, C., Foiani, M., and Haber, J.E. 2001. Regulation of Saccharomyces Rad53 checkpoint kinase during adaptation from DNA damage-induced G2/M arrest. Mol. Cell 7: 293-300.

Petrini, J.H. 2000. The Mre11 complex and ATM: Collaborating to navigate S phase. Curr. Opin. Cell Biol. 12: 293-296.

Povirk, L.F. 1996. DNA damage and mutagenesis by radiomimetic DNA-cleaving agents: Bleomycin, neocarzinostatin and other enediynes. Mutat. Res. 355: 71-89.

Rhind, N. and Russell, P. 2000. Checkpoints: It takes more than time to heal some wounds. Curr. Biol. 10: R908-R911.

Ritchie, K.B. and Petes, T.D. 2000. The Mre11p/Rad50p/Xrs2p complex and the Tellp function in a single pathway for telomere maintenance in yeast. Genetics 155: 475-479.

Rouse, J. and Jackson, S.P. 2000. LCD1: An essential gene involved in checkpoint control and regulation of the MEC1 signalling pathway in Saccharomyces cerevisiae. EMBO I. 19: $5801-5812$.

Saeki, T., Machida, I., and Nakai, S. 1980. Genetic control of diploid recovery after gamma-irradiation in the yeast Saccharomyces cerevisiae. Mutat. Res. 73: 251-265.

Sanchez, Y., Desany, B.A., Jones, W.J., Liu, Q.H., Wang, B., and Elledge, S.J. 1996. Regulation of Rad53 by the Atm-like kinases Mec1 and Tell in yeast cell cycle checkpoint pathways. Science 271: 357-360.

Sanchez, Y., Bachant, J., Wang, H., Hu, F.H., Liu, D., Tetzlaff, M., and Elledge, S.J. 1999. Control of the DNA damage checkpoint by Chk1 and Rad53 protein kinases through distinct mechanisms. Science 286: 1166-1171.

Sassanfar, M. and Roberts, J.W. 1990. Nature of the SOS-inducing signal in Escherichia coli. The involvement of DNA replication. J. Mol. Biol. 212: 79-96.

Siede, W., Friedberg, A.S., Dianova, I., and Friedberg, E.C. 1994 Characterization of G1 checkpoint control in the yeast Saccharomyces cerevisiae following exposure to DNA-damaging agents. Genetics 138: 271-281.

Stewart, G.S., Maser, R.S., Stankovic, T., Bressan, D.A., Kaplan, M.I., Jaspers, N.G.J., Raams, A., Byrd, P.J., Petrini, J.H.J., and Taylor, A.M.R. 1999. The DNA double-strand break repair gene hMRE11 is mutated in individuals with an ataxia-telangiectasia-like disorder. Cell 99: 577-587.

Taalman, R.D., Jaspers, N.G., Scheres, J.M., de Wit, J., and Hustinx, T.W. 1983. Hypersensitivity to ionizing radiation, in vitro, in a new chromosomal breakage disorder, the Nijmegen Breakage Syndrome. Mutat. Res. 112: 23-32.

Usui, T., Ohta, T., Oshiumi, H., Tomizawa, J., Ogawa, H., and Ogawa, T. 1998. Complex formation and functional versatility of Mre11 of budding yeast in recombination. Cell 95: 705-716.

Varon, R., Vissinga, C., Platzer, M., Cerosaletti, K.M., Chrzanowska, K.H., Saar, K., Beckmann, G., Seemanova, E., Cooper, P.R., Nowak, N.J., et al. 1998. Nibrin, a novel DNA double-strand break repair protein, is mutated in Nijmegen breakage syndrome. Cell 93: 467-476.

Weinert, T.A., Kiser, G.L., and Hartwell, L.H. 1994. Mitotic checkpoint genes in budding yeast and the dependence of mitosis on DNA replication and repair. Genes \& Dev. 8: 652-665.

Xiao, Y.H. and Weaver, D.T 1997. Conditional gene targeted deletion by Cre recombinase demonstrates the requirement for the double strand break repair Mre11 protein in murine embryonic stem cells. Nucleic Acids Res. 25: 2985-2991.

Zhu, J., Petersen, S., Tessarollo, L., and Nussenzweig, A. 2001. Targeted disruption of the Nijmegen breakage syndrome gene NBS1 leads to early embryonic lethality in mice. Curr. Biol. 11: 105-109. 


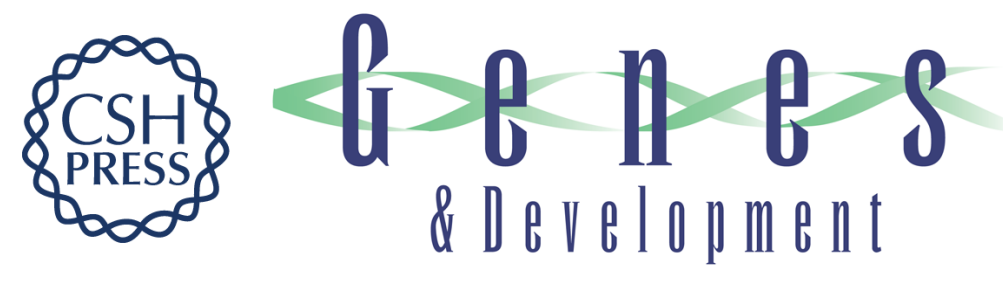

\section{The yeast Xrs2 complex functions in S phase checkpoint regulation}

Damien D'Amours and Stephen P. Jackson

Genes Dev. 2001, 15:

Access the most recent version at doi:10.1101/gad.208701

Supplemental
Material http://genesdev.cshlp.org/content/suppl/2001/09/03/15.17.2238.DC1

References This article cites 44 articles, 20 of which can be accessed free at: http://genesdev.cshlp.org/content/15/17/2238.full.html\#ref-list-1

License

Email Alerting Receive free email alerts when new articles cite this article - sign up in the box at the top Service right corner of the article or click here.

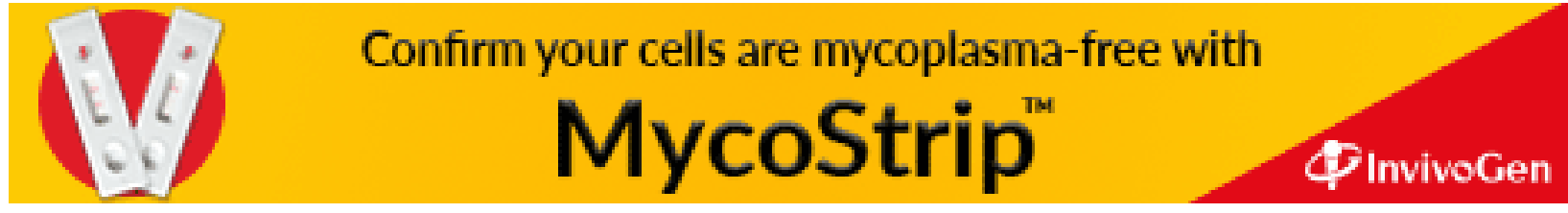

